Academic Platform Journal of Engineering and Science

journal homepage: $\underline{\text { http://apjes.com/ }}$

\title{
Yüzeyi ZnO Nanopartikülleri ile Kaplanmış Demir Matrisli Malzemelerin Karakterizasyonu ve Mekanik Özelliklerinin İncelenmesi
}

\author{
*11Hamza Şimşir \\ ${ }^{1}$ Karabük Üniversitesi, TOBB Meslek Yüksek Okulu Karabük/Türkiye hamzasimsir@karabuk.edu.tr \\ Araştırma Makalesi \\ Geliş Tarihi: 12.12 .2019 \\ Kabul Tarihi: 24.04 .2020
}

$\ddot{O} z$

$\mathrm{Bu}$ çalışmanın amacı toz metalürjisi ile demir ve demir-karbon alaşım malzemelerinin üretilmesi ve bu malzemelerin çinko oksit $(\mathrm{ZnO})$ ile kaplanmasıyla mekanik özelliklerdeki artışı ortaya çıkarmaktır. Bu amaçla, demir ve demir-karbon alaşımı malzemeler toz metalürjisi ile üretilmiştir. Karbon malzeme olarak, aktif karbon, grafit, grafen, karbon nanotüp, vb. gibi yaygın kullanılan karbon malzemelere alternatif olabilecek, glukozdan sentezlenen hidrotermal karbonlar kullanılmıştır. Karbonlu ve karbonsuz demir malzemelerin yüzeyi SILAR metoduyla yaklaşık $200 \pm 17$ nm uzunluğundaki çinko oksit partikülleri tarafından kaplanmıştır. Bu kompozitlerin yapısı SEM, SEM-EDX ve XRD analizleri ile karakterize edilmiştir. Malzemelerin mekanik özelliklerine $\mathrm{ZnO}$ kaplamanın etkisi ise sertlik ve korozyon testleri ile incelenmiştir. Bu sonuçlara göre, ZnO kaplanmış kompozitlerin hem sertlik değerlerinde (\%44 ve \%73) hem de korozyon dayanımlarında (\%118 ve \%60) kaplamasız malzemelere kıyasla önemli derece artış meydana gelmiştir.

Anahtar Kelimeler: Toz metalürjisi, demir, SILAR metodu, çinko oksit.

\section{Characterization and Mechanical Properties of Iron Matrix Materials Coated with ZnO Nanoparticles}

\author{
*11Hamza Şimşir \\ hamzasimsir@karabuk.edu.tr
}

\begin{abstract}
The aim of this study to produce iron and iron-carbon alloys materials by powder metallurgy, and to find out increment of mechanical properties of these materials via zinc oxide $(\mathrm{ZnO})$ coating. For this purpose, iron and iron-carbon alloy materials were produced by powder metallurgy. As the carbon material, hydrothermal carbons derived from glucose were used as an alternative to commonly used carbon materials such as activated carbon, graphite, graphene, carbon nanotube etc. The surface of carbonaceous and carbonless iron materials was coated by $\mathrm{ZnO}$ particles around $200 \pm 17 \mathrm{~nm}$ length by SILAR method. The structure of these composites was characterized by SEM, SEM-EDX and XRD analyzes. The effect of ZnO coating on the mechanical properties of the materials was examined by hardness and corrosion tests. According to these results, both hardness values (44\% and $73 \%$ ) and corrosion resistance (118\% and $60 \%)$ of $\mathrm{ZnO}$ coated composites increased significantly compared to uncoated materials.
\end{abstract}

Keywords: Powder metallurgy, iron, SILAR method, zinc oxide.

\section{GíRiş}

Metal kompozitlerin üretiminde döküm metalürjisinin yanı sıra toz metalürjisi (TM) de yaygın olarak kullanılmaktadır. TM ile üretim; farklı metal tozlarının karıştırılması, preslenmesi ve sinterlenmesi aşamalarında meydana gelmektedir [1]-[3]. Bu yöntem ile metallerin ergitilmesine gerek duyulmadığından döküm metalürjisine kıyasla, özellikle demir gibi ergime noktası yüksek olan metallerden kompozit malzemelerin üretiminde, maliyet açısından önemli bir avantaj sağlamaktadır.

Literatürde, TM ile demir matrisli kompozitler hakkında farklı çalışmalar bulunmaktadır [1]-[4]. Bu çalışmalarda demir matrisine grafit [2], $\mathrm{TiC}$ [1], $\mathrm{SiC}$ [5], Al2O3 [6], vb. gibi farklı tozlar ilave edilmektedir. Bu sayede demir matrisli kompozitlerin mekanik özellikleri ve korozyon dayanımlarında artış meydan gelmektedir. Mekanik 
özelliklerdeki bu artış sadece farklı katkı maddelerinin matris malzemeye ilavesi ile değil, aynı zamanda farklı metal/metal oksit bileşiklerinin malzeme yüzeyine kaplanmasıyla da sağlanabilmektedir. Xie vd. yaptıkları çalışmada sprey piroliz metodu ile paslanmaz çelik yüzeyini demir bazlı amorf toz ile kaplamıştır [7]. Bu malzemelerin sertlik, aşınma özellikleri ve aşınma mekanizması incelendiğinde elde edilen sonuçlara göre; demir bazlı amorf kaplama yüzeyinin arttırılması ile malzemenin sertliğinin arttığı ve düşük aşınma miktarına sahip olduğu belirtilmiştir. Shi vd. yaptıkları çalışmada ise, polianilin-silika nano partikülleri ile kaplanmış Q235 çeliğinin $0,1 \mathrm{M}$ sülfürik asit solüsyonundaki korozyon dayanımını incelemişlerdir [8]. Buna göre kaplama malzemesinin korozyon dayanımını önemli derecede artırdığı ve bu çalışmadaki en yükssek korozyon dayanımın 180 gün sonunda 2,24 x $102 \Omega \mathrm{cm} 2$ olduğu yayınlanmıştır. Kallappa vd. yaptıkları çalışmada ise çinko oksit ( $\mathrm{ZnO})$ nano partikülleri üzerine farkl konsantrasyonlarda seryum(IV) oksit $\left(\mathrm{CeO}_{2}\right)$ partikülleri tutundurmuştur [9]. Zn-CeO2 kompozitlerinin çelik yüzeyine elektroliz ile kaplanması ile elde edilen malzemelerin korozyon dayanımları incelendiğinde, tek bir oran haricinde korozyon dayanımının arttığı görülmüştür.

Çinko (Zn) kaplamalar düşük üretim maliyeti, yüksek aşınma ve korozyon dayanımı özelliklerinden dolayı demir matrisli malzemelerde yaygın olarak kullanılmaktadırlar. Bunlardan özellikle $\mathrm{ZnO}$ bileşikleri yaygın kullanılanlardan bir tanesidir [9], [10]. ZnO bileşikleri atom tabaka biriktirme, kimyasal buhar biriktirme, darbeli lazer biriktirme, püskürtme teknikleri, sprey piroliz, elektro depolama, sol-jel ve SILAR (successive ionic layer adsorption and reaction) gibi yöntemler ile sentezlenebilmektedir [11]-[14]. SILAR metodu, yüzeyi kaplayacak metal iyonlarının (Zn, zirkonyum (Zr), bakır (Cu), vs.) bulunduğu süspansiyon içerisine, kaplanması istenilen altlık malzemenin daldırılması ile metal iyonlarının altlık malzeme yüzeyine adsorpsiyonu ve reaksiyonu sonunda kaplanması prensibine dayanmaktadır [13], [15].

$\mathrm{Bu}$ çalışmada karbon malzeme olarak hidrotermal karbon (HTC) kullanılmıştır. HTC'ler basit şekerlerden atık biyokütlelere kadar çok farklı maddelerden, düşük sıcaklıklarda $\left(180-250{ }^{\circ} \mathrm{C}\right)$, su içerisinde ve geleneksel karbonlara (aktif karbon, grafit, grafen, karbon nanotüp, vb.) kıyasla oldukça düşük üretim maliyetleri ile elde edilebilmektedir [16], [17]. Bu özelliklerinden dolayı geleneksel karbonların yerine HTC'lerin kullanılmasının çalışmaya yenilikçi bir yön katacağı öngörülmüştür. Bu çalışmada kullanılan HTC'lerin sentezi ve karakterizasyonu hakkında bilgiler, yazarın daha önceki çalışmasında detayları ile açıklanmıştır [15]. Yine bu çalışmada toz metalürjisi ile saf demirin ve demir-HTC (\%ağ. 0,4) alaşımının yüzeyine $\mathrm{ZnO}$ nano boyutlu partikülleri SILAR metodu ile kaplanmıştır. Elde edilen kompozitlerin yapısı SEM, SEM-
EDX ve XRD analizleri ile, mekanik özellikleri ise mikro sertlik ve korozyon testleri ile incelenmiştir.

\section{MATERYAL ve METOD}

\subsection{Malzemelerin Üretimi}

Glukozun $200^{\circ} \mathrm{C}$ sicaklıkta, 18 saat süren hidrotermal karbonizasyon ile elde edilen HTC'lerden [16] \%ăg. 0,4 ve geri kalanı demir tozu $(\mathrm{Fe})$ olan karışım, turbula mikserde 1 saat boyunca karıştırılmıştır. Karıştırılan tozlar, 96 ton kapasiteli hidrolik preste ve $700 \mathrm{MPa}$ basınçta preslenmiştir. Preslenen numune, $7{ }^{\circ} \mathrm{C} /$ dakika 1sıtma hızında, $1200{ }^{\circ} \mathrm{C}$ sıcaklıkta, argon gazı altında 1 saat süresince tüp firın içinde sinterlenmiştir (Fe-HTC). Aynı parametrede saf demir tozundan da 2. numune hazırlanmıştır (Saf Fe). Her iki numune de önce zımpara kağıdı ile zımparalanmıştır ve daha sonra numunelerin yüzeyleri parlatılmıştır.

Saf Fe ve Fe-HTC'nin ZnO ile kaplanması için $250 \mathrm{ml}$ hacimli borosilikat cam beher içerisine $100 \mathrm{ml}$ saf suda 0.1 $\mathrm{M} \mathrm{ZnCl}_{2}$ katyonik çözeltisi ve \%29'luk amonyak $\left(\mathrm{NH}_{3}\right)$ çözeltisi ilave edilerek pH 10'a ayarland. Saf Fe ve Fe-HTC; katyonik çözelti içerisinde $30 \mathrm{sn}$., havada $10 \mathrm{sn} ., 90{ }^{\circ} \mathrm{C}$ sicaklıktaki deiyonize suda $30 \mathrm{sn}$. ve son olarak tekrar havada $10 \mathrm{sn}$. bekletildi. Dört adımda gerçekleşen kaplama işlemi $30 \mathrm{kez}$ tekrarlandıktan sonra numuneler, $450{ }^{\circ} \mathrm{C}$ sicaklıktaki firında 1 saat boyunca kalsine edildi. $\mathrm{ZnO}$ kaplanması sirasında meydana gelen muhtemel reaksiyonlar sırasıyla şu şekildedir (Eşitlik 1-4) [18].

$$
\begin{aligned}
& \mathrm{Zn}^{2+}+4 \mathrm{NH}_{4} \mathrm{OH} \rightarrow\left[\mathrm{Zn}\left(\mathrm{NH}_{3}\right)_{4}\right]^{2+}+4 \mathrm{H}_{2} \mathrm{O} \\
& {\left[\mathrm{Zn}\left(\mathrm{NH}_{3}\right)_{4}\right]^{2+}+4 \mathrm{H}_{2} \mathrm{O} \rightarrow \mathrm{Zn}^{2+}+4 \mathrm{NH}_{4}^{+}+4 \mathrm{OH}^{-}} \\
& \mathrm{Zn}^{2+}+2 \mathrm{OH}^{-} \rightarrow \mathrm{Zn}(\mathrm{OH})_{2} \\
& \mathrm{Zn}(\mathrm{OH})_{2} \rightarrow \mathrm{ZnO}+\mathrm{H}_{2} \mathrm{O}
\end{aligned}
$$

\subsection{Malzemelerin Karakterizasyonu}

Mikro yapı analizleri için Zeiss Ultra Plus Taramalı Elektron Mikroskobu (SEM) kullanılmıştır. Yoğunluk hesaplamaları, Archimedes metoduna göre Radwag marka hassas terazi kullanılarak yapılmıştır. Vickers mikro sertlik analizleri için QNESS Q10A+ makinesi kullanılmıştır. Numune üzerine 1 kg yük 15 saniye boyunca uygulanmıştır ve her numune için 5 adet ölçüm yapılmıştır. Potansiyodinamik korozyon testinde ise Parstat 400 Potansiyotat cihazı kullanılmıştır. Üç elektrotlu potansiyotat cihazının karşıt elektrodu grafit, referans elektrodu $\mathrm{Ag} / \mathrm{AgCl}(3,5 \mathrm{~mol} \mathrm{KCl})$ ve çalışma elektrodu ise hazırlanan numunelerdir. Analiz parametreleri olarak ise oda sıcaklığında, \%ă̆. $3.5 \mathrm{NaCl}$ çözeltisinde, 1 $\mathrm{mV} /$ saniye tarama hızında ve $0,5-5,0 \mathrm{~V}$ potansiyel aralığında korozyon testi yapılmıştır. Korozyon yüzey alanı: $0.283 \mathrm{~cm}^{2}$, yoğunluk: $7.80 \mathrm{~g} / \mathrm{cm}^{3}$, ekivalent ağırlık: 18,61 olarak hesaplanmıştır. 


\section{BULGULAR ve TARTIŞMA}

\subsection{SEM, SEM-EDX ve XRD Analizleri ile Malzemelerin Karakterizasyonu}

TM ile üretilen numunelere ait SEM görüntüleri Şekil 1.'de gösterilmiştir. Sadece demir tozu kullanılarak elde edilen numune $\alpha$-ferrit fazından meydana gelmiştir. SEM görüntüsündeki küçük siyah lekeler ise TM ile üretimden sıkça görülen porozitelerdir. Yapılan yoğunluk ölçümü sonunda porozitenin $\% 2$ 'den daha düşük olduğu belirlenmiştir ki bu da TM ile üretilen benzer malzemelere kıyasla oldukça düşük bir değerdir [3], [4]. Saf Fe-HTC yapısında ise $\alpha$-ferrit fazının yanı sıra 3 numaralı bölgede görüldüğü üzere perlit fazı da oluşmuştur (Şekil 1.b). ZnO ile kaplanmış kompozitlerin SEM görüntülerinde ise yaklaşık $200 \pm 17 \mathrm{~nm}$ uzunluğunda $\mathrm{ZnO}$ kristallerinin lamel yapısında tüm yüzeyi hiç boşluk kalmayacak şekilde kapladığı görülmektedir (Şekil 1.c ve Şekil 1.d).
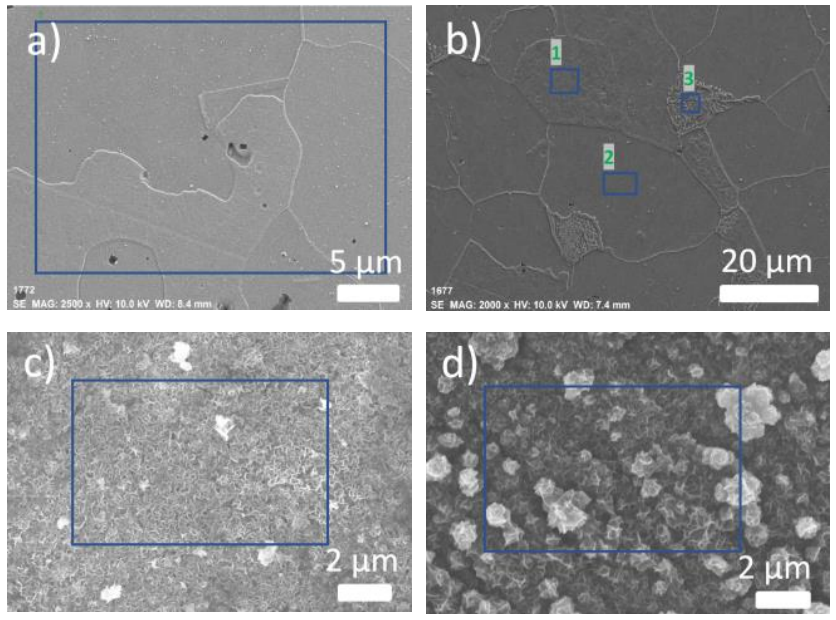

Şekil 1. Numunelere ait SEM görüntüleri a) Saf Fe, b) FeHTC, c)Fe@ZnO ve d)Fe-HTC@ZnO.

Yapılan SEM-EDX analizlerine göre $\mathrm{ZnO}$ ile kaplama yapılmadan önce numunelerdeki demirin ağırlıkça yüzdesi 95,35 ile 97,94 aralığındadır (Tablo 1). Bu numunelerin yüzeyi SILAR metodu ile $\mathrm{ZnO}$ kaplandıktan sonra elde edilen kompozitlerde ise çinko miktarı \%ağ. 30,16-32,99 ve oksijen miktarı ise \%ağ. 24,23-23,18 seviyesine kadar yükselmiştir. SEM-EDX analizi malzemelerin yüzeyi hakkında bilgi verdiğinden dolayı, $\mathrm{ZnO}$ kaplanmış kompozitlere ait atomların ağırlıkça yüzdesi sadece yüzeydeki atomların oranlarını göstermektedir. Ayrıca, FeHTC@ZnO numunesindeki farklı atomlara ait pikler SEMEDX grafiğinde gösterilmiştir (Şekil 2).

Tablo 1. SEM-EDX analizi sonucu yüzeyde bulunan atomların ağırlıkça yüzdeleri.

\begin{tabular}{|l|c|c|c|r|}
\hline Malzeme & $\begin{array}{c}\text { Fe } \\
\text { (\%ag.) }\end{array}$ & $\begin{array}{c}\mathbf{C} \\
\text { (\%ă. })\end{array}$ & $\begin{array}{c}\text { Zn } \\
\text { (\%ă. })\end{array}$ & $\begin{array}{c}\text { O } \\
\text { (\%ag.) }\end{array}$ \\
\hline Saf Fe & 97,94 & - & - & 1,91 \\
\hline Fe-HTC & 95,35 & 3,21 & - & 1,44 \\
\hline Fe@ZnO & 42,78 & - & 32,99 & 24,23 \\
\hline Fe-HTC@ZnO & 43,49 & 3,17 & 30,16 & 23,18 \\
\hline
\end{tabular}

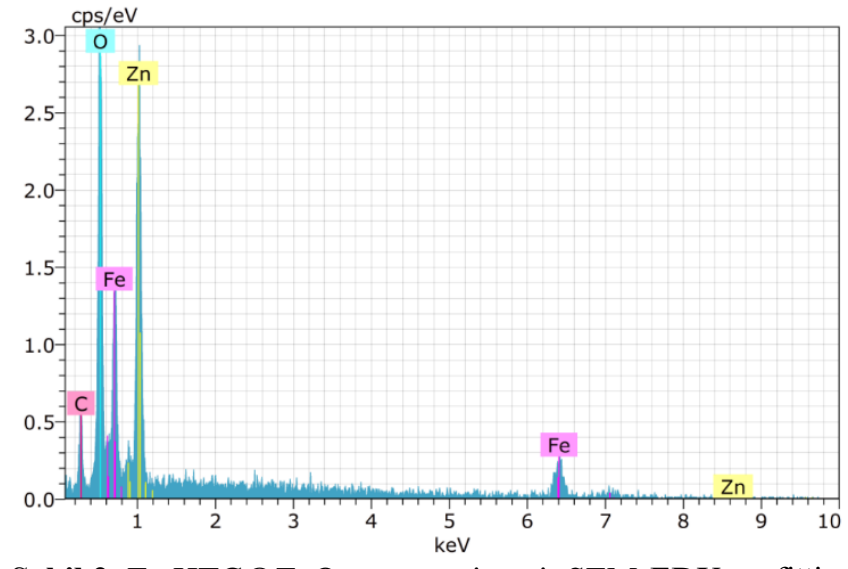

Şekil 2. Fe-HTC@ ZnO numunesine ait SEM-EDX grafiği.

Yüzeyi $\mathrm{ZnO}$ nanopartikülleri ile kaplanmış numunenin yatay kesitinin incelendiği SEM analizi sonucunda ise; kaplama kalınlığının yaklaşık $39 \pm 3 \mu \mathrm{m}$ olduğu belirlenmiştir (Şekil 3). Kaplama kalınlığına kaplayıcı süspansiyonun $\mathrm{pH}^{\prime} 1$ ve konsantrasyonu, numunenin bu süspansiyonuna daldırılma sayısı ve bu süspansiyonda bekletilme süresi gibi pek çok parametre etki etmektedir [12], [18], [19]. Belirlen deney koşullarında istenilen altlık malzemenin kalın bir $\mathrm{ZnO}$ nanopartikül tabakası ile kaplanması mümkündür.

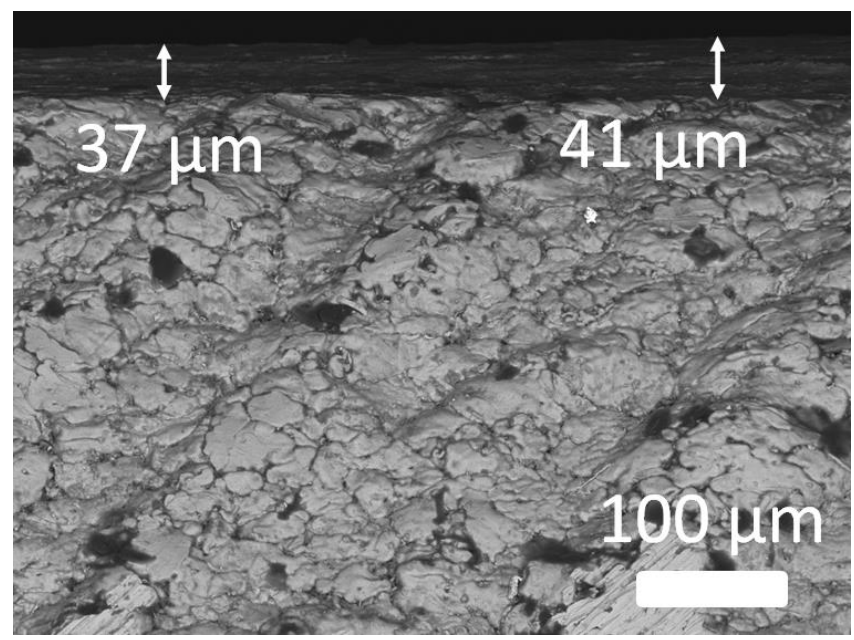

Şekil 3. Fe-HTC@ZnO numunesine ait SEM görüntüsü.

Yapılan XRD analizleri sonunda oluşan X 1şını difraksiyon paternleri incelendiğinde tüm numunelerin 44,66 ve 82 (2$\Theta)$ derecelerinde demir atomlarına ait piklere sahip olduğu ve ana matrisin demir olduğu belirlenmiştir (JCPDS 654899) [20]. Demir tozuna HTC ilave edilmesi ile elde edilen numune de ise hem karbon miktarının çok düşük olmasından hem de bu karbonların amorf yapılı olmasından [17] dolayı herhangi bir yeni pik görülmemiştir (Şekil 4.b). Fakat her iki numunenin $\mathrm{ZnO}$ ile kaplanması ile oluşan kompozit yapıda hem SEM hem de SEM-EDX analizlerinde görüldüğü gibi ZnO kristaline ait pikler (2-Ө: 35, 61) görülmektedir (Şekil 4.c-d). Analiz sonuçları literatürdeki çalışmalar ile kıyaslandığında, yüzeye kaplanan $\mathrm{ZnO}$ kristallerinin c- 
ekseni boyunca yönelim gösteren (002) düzlemine ait kristal yapıda olduğu belirlenmiştir [18].

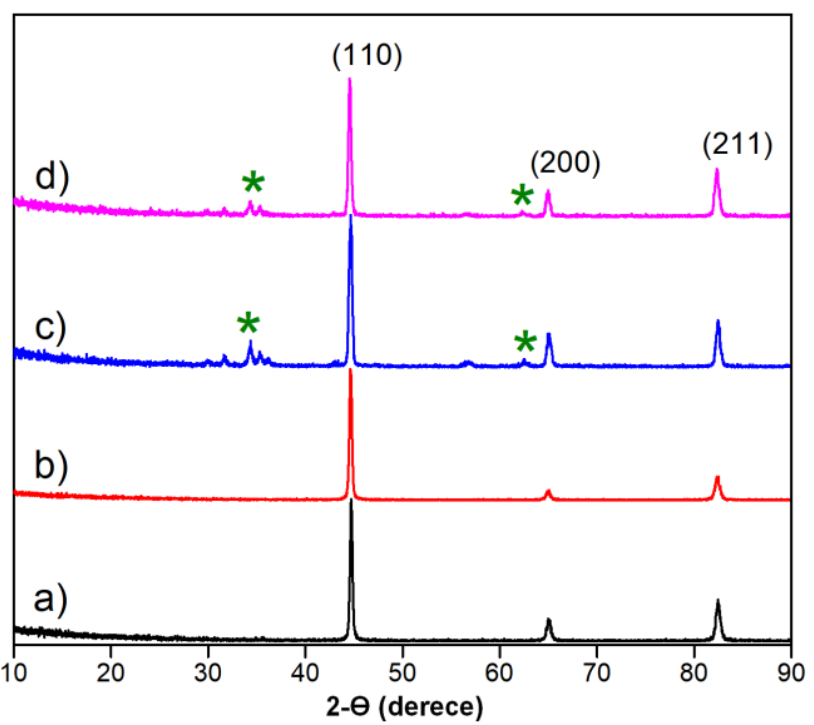

Şekil 4. Numunelere ait $X$ ışını difraksiyon paternleri a) Saf $\mathrm{Fe}, \mathrm{b}) \mathrm{Fe}-\mathrm{HTC}$, c) Fe@ZnO ve d) HTC-Fe@ZnO.

\subsection{Sertlik ve Korozyon Testleri Sonuçları}

Yapılan Vickers mikro sertlik deneyine göre, saf demir tozundan elde edilen numune 57,3 $\pm 2,1 \mathrm{Hv}$ sertlik değerine sahiptir (Şekil 5). Bu numunenin yüzeyi $\mathrm{ZnO}$ kristali ile kaplandığında sertlik değeri $82,6 \pm 2,7 \quad \mathrm{Hv}$ değerine ulaşmıştır. Fe-HTC numunesinin sertlik değeri de $(75 \pm 3,7$ $\mathrm{Hv}$ ) benzer şekilde kaplamanın etkisi ile 130,3 $\pm 2,9 \mathrm{Hv}$ değerine yükselmiştir. Hem saf $\mathrm{Fe}$, hem de Fe-HTC malzemelerinin yüzeyine $\mathrm{ZnO}$ kaplanmasının etkisi ile her iki malzemenin sertlik değerlerinde önemli bir artış görülmüştür.

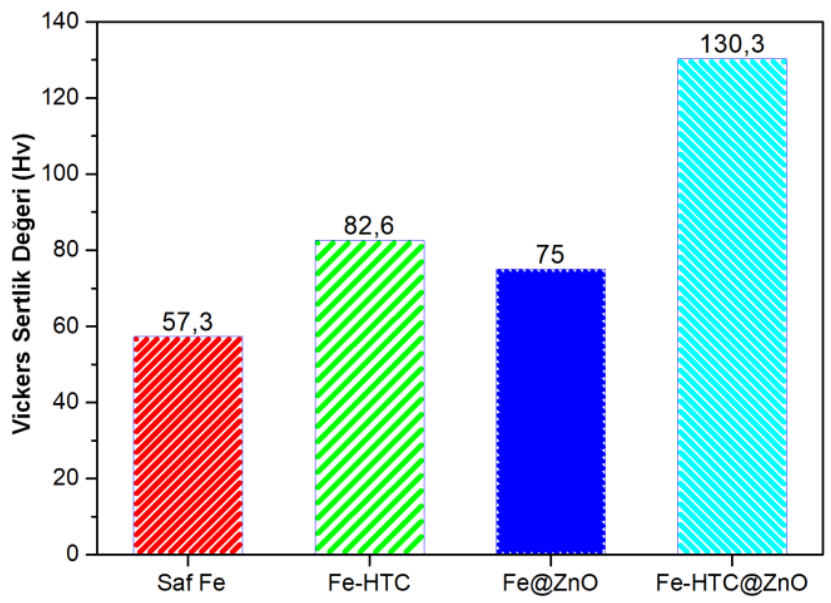

Şekil 5. Numunelere ait Vickers sertlik deneyi sonuçları.

Seramik bazlı kaplamaların ana matris malzemenin sertlik özelliğini artırdığı, bu artış miktarımın ise matris ile kaplama malzemesinin yapmış olduğu bağ kuvvetine bağlı olduğu literatürden bilinmektedir [21]. Yapısında karbon bulanan Fe-HTC kompozitinin sertlik değerinin \%42'lik artışın sebebinin $\mathrm{ZnO}$ ile $\mathrm{C}$ arasında oluşan bağ ya da etkileşimden kaynaklandığı düşünülmektedir. Yine yapılan benzer çalışmalardan, sinterlemenin mekanik kilitlenme (interlokasyon) ve kimyasal bağlanmaya sebep olduğu ve böylece mekanik özelliklerin geliştiği bilinmektedir [22]. Yine karbon atomlarınn bu mekanizmaya olumlu etkilerinin de meydana gelmiş olabileceği öngörülmektedir.

3,5 $\mathrm{M} \mathrm{NaCl}$ çözeltisinde yapılan korozyon testi sonucunda elde edilen potansiyo-dinamik polarizasyon eğrileri Şekil 6.'da gösterilmiştir. Tafel ekstrapolasyonu yöntemi ile aynı anda gerçekleşen anodik ve katodik reaksiyonların birbirine karıştığ 1 nokta tafel eğrileri çizilerek bulunmuştur. $\mathrm{Bu}$ eğrilerin kesiştiği potansiyel değeri korozyon potansiyelini (Ecorr), akım değeri ise korozyon akımını (Icorr) göstermektedir [23]. Numunelerin korozyon potansiyelleri (Ecorr), korozyon akım yoğunlukları ve korozyon oranları Tablo 2'de gösterilmiştir. Numunelere ait korozyon oranları ise ASTM-G012-89 standardına göre hesaplanmıştır (Eşitlik 1) [24], [25].

Korozyon Oranı $=\frac{K \times i_{\text {corr }} \times E A}{\text { Yoğunluk }}$

(Eşitlik 1)

$K$ metrik dönüşüm faktörü $=3,27 \times 10^{-3}(\mathrm{~mm} \times \mathrm{gr}) /(\mu \mathrm{A} \mathrm{x} \mathrm{cm}$ $\mathrm{x}$ yıl), EA ise ekivalent ağırlıktır ve Eşitlik 2'ye göre hesaplanmıştır.

Ekivalent a $\breve{\mathrm{g}} \iota r l l k=\left\{\sum \frac{f_{i} \times n_{i}}{w_{i}}\right\}^{-1}$

$f_{i}$ kütle kesri, $n_{i}$ kompozitteki valans element, $w_{i}$ ise atomik ağırlıktır [25], [26].

Saf demir tozlarından elde edilen numunenin korozyon dayanımı, HTC ilavesi ile azaldığı görülmüştür. Bunun sebebinin, Fe-HTC'nin iki fazlı yapıya sahip olması ( $\alpha$-ferrit ve perlit) ve bundan dolayı da galvanik korozyona sebep olarak korozyon hızını artırmış olabileceği düşünülmektedir [23], [27].

Tablo 2. Numunelere ait korozyon testi sonuçları.

\begin{tabular}{|l|l|l|c|}
\hline Malzeme & $\begin{array}{l}\text { Korozyon } \\
\text { Potansiyeli } \\
(\mathbf{V})\end{array}$ & $\begin{array}{l}\text { Korozyon } \\
\text { Akım } \\
\text { Yoğunluğu } \\
\left(\boldsymbol{\mu A} / \mathbf{c m}^{2}\right)\end{array}$ & $\begin{array}{l}\text { Korozyon } \\
\text { Oranı } \\
(\mathbf{m m} / \mathbf{y ı l}\end{array}$ \\
\hline Saf Fe & $-0,40$ & 124,09 & 0,96 \\
\hline Fe-HTC & $-0,47$ & 246,81 & 1,91 \\
\hline Fe@ZnO & $-0,49$ & 58,02 & 0,44 \\
\hline Fe-HTC@ZnO & $-0,55$ & 154,37 & 1,19 \\
\hline
\end{tabular}

Korozyon dayanımları sirasıyla 0,96 ve $1,91 \mathrm{~mm} / \mathrm{y} 1 \mathrm{l}$ olan Saf $\mathrm{Fe}$ ve Fe-HTC numunelerinin $\mathrm{ZnO}$ ile kaplanması ile elde edilen numunelerin korozyon dayanımları 0,44 ve 1,19 $\mathrm{mm} / \mathrm{y}$ ıl olarak tespit edilmiştir (Tablo 2). Numunelerin yüzeyini kaplayan $\mathrm{ZnO}$ tabakasının korozyon dayanımı demire kıyasla daha yüksek olduğu ve malzemelerin sertlik 
değerlerinde olduğu gibi korozyon dayanımına da önemli derecede olumlu katkı sağladığı belirlenmiştir.

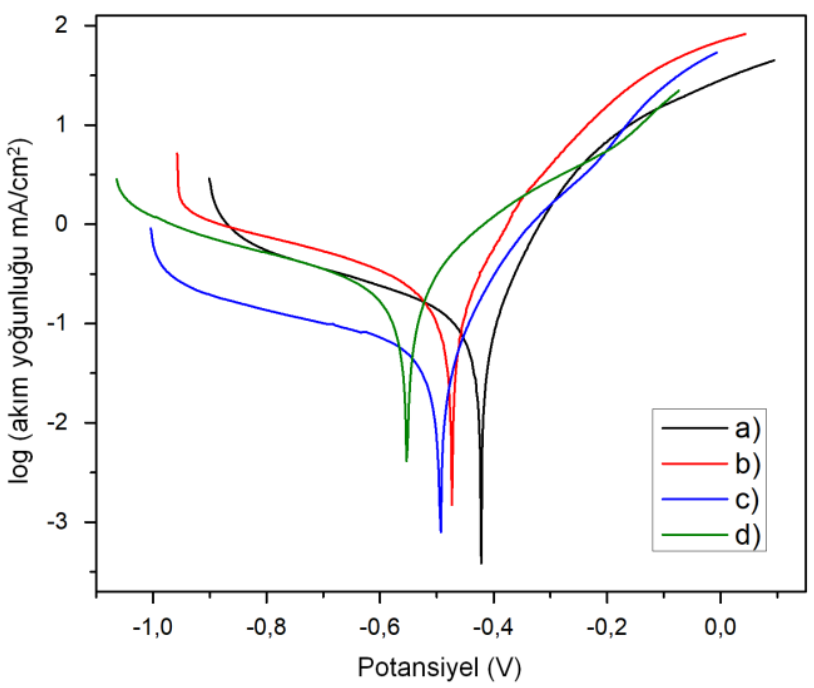

Şekil 6. Potansiyo-dinamik polarizasyon eğrileri a) Saf Fe, b) Fe-HTC, c) Fe@ZnO ve d) HTC-Fe@ZnO.

\section{SONUÇLAR}

$\mathrm{Bu}$ çalıșmada toz metalürjisi ile demir ve demir-karbon tozlarından malzemeler elde edilmiş ve bu malzemelerin yüzeyi SILAR metodu kullanılarak $\mathrm{ZnO}$ ile kaplanmıştır. Yapılan analizlerin sonuçlarını şu şekilde maddelemek mümkündür;

- Toz metalürjisi ile üretilen demir ve demir-karbon yapılı malzemelerin yüzeyi SILAR metoduyla üretilen, $200 \pm 17 \quad \mathrm{~nm}$ boyutlarındaki $\mathrm{ZnO}$ partikülleri ile kaplanmıştır.

- ZnO kaplamanın etkisi ile Saf Fe ve Fe-HTC'nin numunelerinin sertlik değerlerinde sırasıyla yaklaşı1k \%44 ve \%73 artış meydana gelmiştir.

- Yüzeyleri ZnO kaplanmış kompozitlerin korozyon dayanımları, kaplamasız malzemelere kıyasla yaklaşık $\% 118$ ve $\% 60$ oranında artmıştır.

Elde edilen sonuçların 1şığında, demir matrisli malzemelerin yüzeyini, SILAR metoduyla oldukça kolay ve düşük üretim maliyetlerinde $\mathrm{ZnO}$ partikülleri ile kaplamak mümkündür. Kaplamanın etkisi ile malzemelerin hem mekanik özellikleri hem de korozyon dayanımları olumlu yönde etkilenmektedir.

\section{KAYNAKÇA}

[1] L. Zhong, Y. Xu, M. Hojamberdiev, J. Wang, and J. Wang, 'In situ fabrication of titanium carbide particulatesreinforced iron matrix composites', Materials \& design, vol. 32, no. 7, pp. 3790-3795, 2011.

[2] X. Zhang, F. Ma, K. Ma, and X. Li, 'Effects of graphite content and temperature on microstructure and mechanical properties of Iron-based powder metallurgy parts', Journal of Materials Science Research, vol. 1, no. 4, p. 48, 2012.
[3] M. A. Erden, S. Gündüz, M. Türkmen, and H. Karabulut, 'Microstructural characterization and mechanical properties of microalloyed powder metallurgy steels', Materials Science and Engineering: A, vol. 616, pp. 201-206, 2014.

[4] M. Türkmen, H. Karabulut, M. A. Erden, and S. Gündüz, 'EFFECT OF TIN ADDITION ON THE MICROSTRUCTURE AND MECHANICAL PROPERTIES OF PM STEELS', Technological Applied Sciences, vol. 12, no. 4, pp. 178-184.

[5] C. Krishnamurthy Srinivasa, C. Suryanarayana Ramesh, and S. K. Prabhakar, 'Blending of iron and silicon carbide powders for producing metal matrix composites by laser sintering process', Rapid Prototyping Journal, vol. 16, no. 4, pp. 258-267, 2010.

[6] P. Gupta, D. Kumar, M. A. Quraishi, and O. Parkash, 'Corrosion behavior of $\mathrm{Al} 2 \mathrm{O} 3$ reinforced Fe metal matrix nanocomposites produced by powder metallurgy technique', Advanced Science, Engineering and Medicine, vol. 5, no. 4, pp. 366-370, 2013.

[7] L. Xie, X. Xiong, Y. Zeng, and Y. Wang, 'The wear properties and mechanism of detonation sprayed iron-based amorphous coating', Surface and Coatings Technology, vol. 366, pp. 146-155, 2019.

[8] S. Shi, Y. Zhao, Z. Zhang, and L. Yu, 'Corrosion protection of a novel SiO2@ PANI coating for Q235 carbon steel', Progress in Organic Coatings, vol. 132, pp. 227-234, 2019.

[9] D. Kallappa and V. T. Venkatarangaiah, 'Synthesis of $\mathrm{CeO} 2$ doped $\mathrm{ZnO}$ nanoparticles and their application in $\mathrm{Zn}$ composite coating on mild steel', Arabian Journal of Chemistry, 2018.

[10] L. Exbrayat et al., 'Electrodeposition of zinc-ceria nanocomposite coatings in alkaline bath', Journal of Solid State Electrochemistry, vol. 18, no. 1, pp. 223-233, 2014.

[11] A. Mahmood and A. Naeem, 'Sol-Gel-Derived Doped ZnO Thin Films: Processing, Properties, and Applications', Recent Applications in Sol-Gel Synthesis, pp. 169-193, 2017.

[12] L. Znaidi, 'Sol-gel-deposited $\mathrm{ZnO}$ thin films: A review', Materials Science and Engineering: B, vol. 174, no. 1-3, pp. 18-30, 2010.

[13] C. Duman and H. Guney, 'Influence of annealing and optical aging on optical and structural properties of $\mathrm{ZnO}$ thin films obtained by SILAR method', Lithuanian Journal of Physics, vol. 57, no. 4, 2017.

[14] Ş. Duman and B. Özkal, 'Farklı Püskürtmeli Kurutucu Proses Parametreleri ve Çözelti Konsantrasyonunda ZnO Nanopartiküllerin Sentezlenmesi ve Karakterizasyonu', Akademik Platform Mühendislik ve Fen Bilimleri Dergisi, vol. 7, no. 2, pp. 324-331.

[15] A. Raidou et al., 'Characterization of $\mathrm{ZnO}$ thin films grown by SILAR method', Open Access Library Journal, vol. 1, no. 3, 2014.

[16] H. Simsir, N. Eltugral, and S. Karagoz, 'Hydrothermal carbonization for the preparation of hydrochars from glucose, cellulose, chitin, chitosan and wood chips via low-temperature and their characterization', Bioresource technology, vol. 246, pp. 82-87, 2017. 
[17] M.-M. Titirici, R. J. White, C. Falco, and M. Sevilla, 'Black perspectives for a green future: hydrothermal carbons for environment protection and energy storage', Energy \& Environmental Science, vol. 5, no. 5, pp. 67966822, 2012.

[18] P.-Y. Lee, S.-P. Chang, and S.-J. Chang, 'Synthesis and optical properties of $\mathrm{ZnO}$ thin films prepared by SILAR method with ethylene glycol', Advances in nano research, vol. 1, no. 2, pp. 93-103, 2013.

[19] P. U. Londhe and N. B. Chaure, 'Effect of $\mathrm{pH}$ on the properties of electrochemically prepared $\mathrm{ZnO}$ thin films', Materials Science in Semiconductor Processing, vol. 60, pp. 5-15, 2017.

[20] W.-S. Lin, H.-M. Lin, H.-H. Chen, Y.-K. Hwu, and Y.-J. Chiou, 'Shape effects of iron nanowires on hyperthermia treatment', Journal of Nanomaterials, vol. 2013, p. 9, 2013.

[21] O. S. Fayomi, 'Effect of composite particulate reinforcement on the morphology, anti-corrosion and hardness properties of fabricated $\mathrm{Zn}-\mathrm{ZnO}$ coatings', J. Mater. Environ. Sci., vol. 6, pp. 963-968, 2015.

[22] K. P. Ananth, J. Sun, and J. Bai, 'An innovative approach to manganese-substituted hydroxyapatite coating on zinc oxide-coated 316L SS for implant application',
International journal of molecular sciences, vol. 19, no. 8, p. 2340, 2018.

[23] Y.-S. Kim and J.-G. Kim, 'Corrosion behavior of pipeline carbon steel under different iron oxide deposits in the district heating system', Metals, vol. 7, no. 5, p. 182, 2017.

[24] E. Otero, A. Pardo, M. V. Utrilla, E. Saenz, and J. F. Alvarez, 'Corrosion behaviour of AISI 304L and 316L stainless steels prepared by powder metallurgy in the presence of sulphuric and phosphoric acid', Corrosion Science, vol. 40, no. 8, pp. 1421-1434, 1998.

[25] H. Simsir, Y. Akgul, and M. A. Erden, 'Hydrothermal carbon effect on iron matrix composites produced by powder metallurgy', Materials Chemistry and Physics, p. 122557, 2019.

[26] A. Ayyagari, V. Hasannaeimi, H. S. Grewal, H. Arora, and S. Mukherjee, 'Corrosion, erosion and wear behavior of complex concentrated alloys: a review', Metals, vol. 8, no. 8, p. 603, 2018.

[27] Y. Y. Li, Z. Z. Wang, X. P. Guo, and G. A. Zhang, 'Galvanic corrosion between N80 carbon steel and $13 \mathrm{Cr}$ stainless steel under supercritical CO2 conditions', Corrosion Science, vol. 147, pp. 260-272, 2019. 